\title{
O conhecimento das ideias em Schopenhauer
}

Thiago de Souza Salvio ${ }^{*}$

Resumo: O intuito da presente comunicação é deslindar os conceitos fundamentais do que podemos denominar a "Filosofia da Arte" do pensador alemão Arthur Schopenhauer. Este tema propriamente dito não leva o título considerado acima, mas outrossim, "Metafísica do Belo"; com as noções de Ideia, Vontade, Sujeito puro do conhecimento, Gênio, buscaremos obter a compreensão do conhecimento ideal que o autor em pauta entende por contemplação estética, para isto, vamos examinar seus textos principais. Palavras-chave: Filosofia da Arte; Metafísica do Belo; Ideias; Schopenhauer.

\section{The Knowledge of the Ideas in Schopenhauer}

Abstract: The purpose of this communication is to unravel the fundamental concepts of what we can call the "Philosophy of Art" of the German thinker Arthur Schopenhauer. This theme itself does not take the title considered above, but otherwise, "Metaphysics of the Beautiful"; with the notions of Idea, Will, Pure subject of knowledge, Genius, we will seek to obtain the understanding of the ideal knowledge that the author in question understands by aesthetic contemplation, for this, we will examine his main texts. Key-words: Philosophy of Art; Metaphysics of the Beautiful; Ideas; Schopenhauer.

\section{Introdução}

No terceiro livro de Die Welt als Wille und Vorstellung [O Mundo como Vontade e Representação], o filósofo alemão Arthur Schopenhauer (1788-1860) se dedica no interior de seu sistema filosófico, ao exame do que ele denomina Metaphysik des Schönen [Metafísica do Belo]. De acordo com ele, a estética relaciona-se com a metafísica do belo como a física se relaciona com a metafísica da natureza. A primeira ensina o caminho pelo qual o efeito do belo é atingido, dá regras às artes, segundo as quais elas devem criar o belo. "A metafísica do belo, entretanto, investiga a essência íntima da beleza, tanto no que diz respeito ao sujeito que

\footnotetext{
* Mestrando pelo Programa de Pós-graduação em Filosofia da FFC - Unesp/ Marília, orientado pelo Prof. Dr. Marcio Benchimol Barros. O presente trabalho foi realizado com apoio da Coordenação de Aperfeiçoamento de Pessoal de Nível Superior - Brasil (CAPES) - Código de Financiamento 001.E-mail: thiagosouzasalvio@ gmail.com.
} 
possui a sensação do belo quanto ao objeto que a ocasiona”. O conteúdo do objeto de

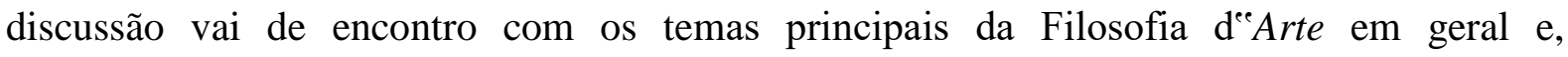
concernente à obra do autor em pauta, é fortemente corroborado pelas „Preleções de Berlime (1820) bem como pelos Ergänzunen [Suplementos] (1844) que configuram o segundo tomo da magnum opus supracitada. Sem embargo,vamos nos atentar à proposta de concentrarmos em compreender o conceito schopenhaueriano de contemplação estética; para isto, vamos assumir uma chave-de-leitura voltada aos fundamentos da Teoria Platônica das Ideias contrastada com a distinção idealista kantiana entre fenômeno [Erscheinung] e coisa-em-si [Ding an sich], ambas respeitadas pelo pensador pessimista, mas filosoficamente incorporada a sua maneira.

I.

Are not the mountains, waves and skies, a part Of me and of my soul, as I of them?

(Não são as montanhas, ondas e nuvens, como uma parte/ De mim e de minha alma, como eu para elas?) - Lord Byron

A terceira consideração ${ }^{1}$ sui generis de Schopenhauer em $O$ Mundo como Vontade e Representação é: "A representação independente do princípio de razão: A ideia platônica: o objeto da arte". Apresentado no primeiro livro como mera representação, objeto para um sujeito, o mundo, no segundo livro é considerado por sua outra face e podemos verificar como este é Vontade ${ }^{2}$ que unicamente se mostrou como o que aquele mundo é além da representação; em conformidade, denominava-se o mundo como representação, no todo ou em suas partes, a objetidade ${ }^{3} d a$ Vontade [Objektität des Willens], quer dizer: a Vontade tornada objeto, isto é, representação. Recordamos também que tal objetivação da vontade possuía graus numerosos, porém determinados, em que, com clareza e perfeição gradualmente crescente, a vontade surgia na representação; se apresentava como objeto. Reconhecemos as ideias de Platão em tais graduações, na medida em que estas são as espécies determinadas, ou as formas e propriedades invariáveis originárias de todos os corpos

\footnotetext{
${ }^{1}$ Este é o tema exclusivo do terceiro livro cujos desdobramentos suplementares se coadunam respectivamente ao segundo tomo da obra magna de Schopenhauer, Die Welt als Wille und Vorstellung.

2 Enfatizemos doravante o significado substancial ao atribuído "V" (maiúsculo), dada a onipotência metafísico-cosmológica da Vontade. Quando utilizado "v" (minúsculo) trata-se da vontade enquanto atividade motriz do sujeito volitivo, ou seja, impelido por motivações no seu agir. O mesmo caso vale para as Ideias $(s)$ porém tanto no singular quanto no plural manteremos o início maiúsculo, preservando sua "identidade metafísica" na singularidade e na pluralidade.

${ }^{3}$ Não à toa objetidade, pois o termo diz respeito ao caráter "objetal" da Vontade gradativamente fazer-se objeto.
} 
naturais, orgânicos ou inorgânicos, como também as forças genéricas se manifestando conforme leis naturais.

Tais Ideias [Ideen], portanto, se manifestam em indivíduos e particularidades inumeráveis, comportando-se como modelo para estas suas imagens. A multiplicidade de tais indivíduos é concebível unicamente mediante o tempo e o espaço, seu surgir e desaparecer unicamente mediante a causalidade, em cujas formas reconhecemos somente as diversas modalidades do princípio de razão, princípio último de toda finitude, toda individuação, forma geral da representação, tal como esta se dá na consciência do indivíduo como tal. A Ideia, porém, não se submete àquele princípio: por isto não experimenta pluralidade nem mudança. Enquanto os indivíduos em que se manifesta são inumeráveis e nascem e perecem incessantemente, ela permanece invariavelmente a mesma, e para ela o princípio de razão não possui significado algum. Mas como este é a forma sob a qual se encontra todo conhecimento do sujeito, enquanto este conhece como indivíduo, assim as ideias se localizam totalmente fora da esfera do conhecimento do sujeito como tal. Portanto, se as ideias devem se tornar objeto do conhecimento, a condição é a supressão da individualidade no sujeito cognoscente (SCHOPENHAUER, 1999, p. 21).

Antes de avançarmos, seja feita a seguinte observação essencial: aquilo que é denominado coisa em si na filosofia de Kant, é introduzida em sua doutrina de maneira paradoxal, quando atingido pelo caminho bem diverso proposto por Schopenhauer, é reconhecido como Vontade, na esfera deste conceito ampliado e determinado do modo indicado. além disto, que não se hesite em reconhecer, feita a exposição precedente, nos graus determinados da objetivação desta vontade, que é o em-si do mundo, aquilo que Platão denominou as idéias eternas, ou as formas imutáveis [ $\varepsilon 1 \delta \eta]$.

Sendo a vontade a coisa em si, e a ideia a objetidade imediata desta Vontade em um grau determinado, nos encontramos com a coisa em si de Kant e a ideia de Platão, única que

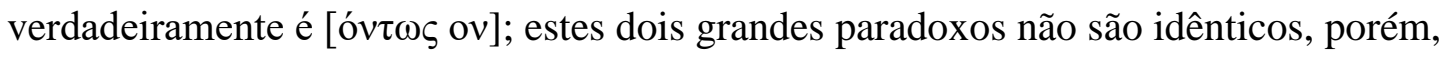
estreitamente afins. A doutrina platônica das ideias e da coisa em si kantiana, quando comparadas, possuem acordo profundo.

Segundo o filósofo de Frankfurt (SCHOPENHAUER, 1997, p. 22) conhecemos a Vontade como a coisa-em-si; a Ideia, entretanto, como a objetidade imediata (isto é, que ainda não entrou no tempo e no espaço) da Vontade num determinado grau. Portanto, ambas não são a mesma coisa, porém intimamente aparentadas: divergem apenas mediante uma determinação, a citar: a Ideia é a Vontade assim que esta se tornou objeto, contudo ainda não entrou no espaço, no tempo e na causalidade. Espaço, tempo e causalidade não concernem à 
Ideia, tampouco à Vontade. Mas à Ideia já concerne o ser-objeto, à Vontade não. A bem dizer, a doutrina de Platão das Ideias e seu ser eterno, isto é, inatingível pelo devir e pelo perecer, é idêntica à doutrina da idealidade do espaço, tempo e causalidade de Kant.

Ambos declaram o mundo visível, o mundo da experiência, um mero fenômeno, que em si é nulo, e possui significação e realidade emprestada apenas mediante o que nele se expressa. Este que nele se expressa é, portanto, o oposto do fenômeno: para Kant, a coisa-emsi; para Platão, a Ideia. Apenas a estas conferem ambos o ser verdadeiro, recusam-lhes por completo, todavia, todas as formas do fenômeno, inclusive a mais simples e universal. A diferença da exposição reside em que Kant a realiza de maneira direta, enquanto Platão, de maneira indireta. De fato, Kant, para negar essas formas, concebeu-as imediatamente em expressões abstratas, isentando a coisa-em-si de tempo, espaço e causalidade, como sendo meras formas do fenômeno; em relação à coisa-em-si, elas não possuem significação alguma, não são nada. Platão não chegou até essa expressão superior, e só indiretamente pôde isentar as Ideias (o oposto do fenômeno) daquelas formas, a saber, ele o fez na medida em que nega às Ideias o que é possível somente mediante aquelas formas, ou seja, a pluralidade do que é homogêneo, o nascer e perecer, a mudança.

A opinião geral dos sábios do século XIX é que Platão e Kant são os filósofos mais divergentes. De fato, tais sábios se prenderam como de hábito o fazem, às palavras; eles encontraram em Kant as expressões: "representações a priori; formas da intuição e do pensamento que se encontram em nós independentemente da experiência; conceitos originários do entendimento puro”. Em Platão encontraram o discurso sobre as Ideias, as quais são conceitos originários, que devem ser recordações de uma intuição, anterior à vida, das coisas verdadeiras. Então eles se perguntaram se as Ideias de Platão e as formas a priori de Kant não seriam a mesma coisa. Portanto, essas duas doutrinas no todo heterogêneas, a kantiana das formas, que limitam o conhecimento do indivíduo ao fenômeno, e a platônica das Ideias, cujo conhecimento justamente aquelas formas negam expressamente, essas duas doutrinas, nesse sentido tão diametralmente opostas, foram, por se assemelharem um pouco em suas expressões atentamente cotejadas (SCHOPENHAUER, 2003, p. 34).

A Ideia é a objetidade da Vontade, porém imediata e, por conseguinte, adequada a coisa-em-si, segundo Kant, deve ser livre de todas as formas vinculadas ao conhecer enquanto tal. Entre tais formas, ele teria antes de tudo incluir a do ser-objeto para um sujeito, pois exatamente esta é a forma mais universal de todo fenômeno, isto é, de toda representação. Se estabelece assim a essencial diferença entre a Ideia e a coisa em si: essa é a 
manifestação imediata dela fora do princípio de razão suficiente: figuras a priori do intelecto (tempo, espaço e causalidade) válidas universalmente para a possibilidade da experiência.

II.

Em correspondência ao seu "apóstolo" " Johann August Becker enviada de Frankfurt, datada em 31 de Março de 1854, Schopenhauer se explica de maneira veemente escrevendo o seguinte:

Nos parágrafos 32 e 34 do primeiro tomo de minha obra principal se encontra exposta de maneira clara a relação entre a Ideia e a coisa em si. Em poucas palavras o que digo é isto: a ideia platônica não é mais que a representação intuitiva, é dizer, a aparência mesma, compreendida como um nível de objetivação da Vontade, que se encontra liberta da multiplicidade do homogêneo presente no espaço e no tempo, e que por conseguinte se encontra liberta do aleatório, do diverso e do imperfeito. Captar esta Ideia requer a eliminação da Vontade da consciência, mas isto não pode dar-se a partir da vontade mesma, por conseguinte apenas através duma

momentânea preponderância do intelecto. A especial significação das ideias particulares, como as figuras animais e suas partes e formas, como expus em "Vontade na Natureza", é mera comprovação empírica de minha verdade fundamental pressuposta aqui, que a coisa em si é essa aparência da vontade de viver que nós vemos aqui sob diferentes condições e nos adaptamos a elas (SCHOPENHAUER, 1883, p. 98 (trad. do autor) ${ }^{5}$.

O conhecimento em geral pertence ele próprio à objetivação da Vontade em seus graus mais elevados, e que a sensibilidade, os nervos, o cérebro, como outras partes do ser orgânico, constituem apenas expressão dela nesse grau de sua objetividade, portanto, a representação por ela produzida está igualmente destinada ao serviço daquela como um meio para atingir agora, seus complexos fins, para a manutenção de um ser provido de múltiplas necessidades.

O conhecimento tanto quanto está a serviço da Vontade, atinge apenas as relações das coisas resultantes de sua submissão ao princípio de razão. Originalmente, portanto, e conforme sua essência, o conhecimento é útil à vontade, e, assim como o objeto imediato que, com a aplicação da lei da causalidade se torna seu ponto de partida, é somente vontade objetivada, assim também todo conhecimento resultante do princípio de razão se mantém

\footnotetext{
${ }^{4}$ Para a distinção entre apóstolos e discípulos de Schopenhauer, vale conferir o artigo de Durante: "A Escola de Schopenhauer em seus sentidos lato e estrito: entre Apóstolos, Evangelistas, Metafísicos, Heréticos, os Pais da Igreja e as Mulheres".

${ }^{5}$ Im ersten Band meines Hauptwerks findet man in $\S .32$ u. 34 das Verhältniß der Idee zum Ding an Sich deutlich dargelegt. Im Ganzen würde ich sagen: Die Platonische Idee ist eben nur die anschaunliche Vorstellung, also die Erscheinung selbst, aufgefaßt als eine Stufe der Objektivation des Willens und dadurch befreit von der Vervielfältigung des Gleichartigen durch Raum und Zeit und von den durch eben diese herbeigeführten Zufälligkeiten, Mängeln und Unvollkommenheiten. Ihre Auffassung erfordert die Elimination des Willens aus dem Bewußtseyn, die aber als solche nicht vom Willen selbst ausgehn kann, folglich nur durch eine momentane Präponderanz des Intellekts eintritt. Die specielle Bedeutung der einzelnen Ideen, Thiergestalten und ihrer Theile und Formen, wie ich sie im "Willen der Natur" dargelegt habe, ist bloß die empirische Bestätigung meiner dabei vorausgesetzten Grundwahrheit, daß das Ding an sich dieser Erscheinung der Wille zum Leben ist, den wir hier unter verschiedenen Bedingungen auftreten und ihnen sich anpassen sehn (Briefwechsel zwischen Arthur Schopenhauer und Johann August Becker).
} 
numa relação mais ou menos estreita com a vontade. Pois o indivíduo encontra seu corpo como um objeto entre objetos, com todos eles mantendo variadas relações e proporções conforme o princípio de razão, cuja observação, portanto, por vias mais ou menos extensas, sempre reconduz ao seu corpo, logo à sua vontade. Como é o princípio de razão que situa os objetos nesta relação com o corpo, e por isto com a vontade, o conhecimento servidor desta também se empenhará unicamente em conhecer dos objetos, justamente as proporções estabelecidas pelo princípio de razão suficiente.

Segundo Pernin (1995) a análise do elemento objetivo é necessariamente incompleta, pois a Ideia e o sujeito cognoscente puro "formam juntos a objetidade adequada da Vontade nesse grau". A Ideia é superior aos seus fenômenos, que permanecem submetidos às formas do princípio de razão suficiente e inferior à Vontade como coisa em si. Esse tríplice nível define a problemática. A generalidade da Ideia não deve ser confundida com a do conceito abstrato. A Ideia recolhe a multiplicidade espaço-temporal em uma unidade anterior a esta; ela escapa de toda as formas plurais as quais o princpium individuationis [princípio de individuação] $^{6}$ é responsável, ela é indiferente aos indivíduos, assim como ao seu número, e só é dada àquele que cessa momentaneamente de ser indivíduo.

Como vimos, a doutrina de Schopenhauer é como sendo de acordo com a platônica; as Ideias são atingidas pela contemplação inteligível que se eleva acima do mundo sensível das aparências, fenômenos que são apenas cópias múltiplas, efêmeras e imperfeitas de paradigmas imutáveis; enfatizando principalmente a relação expressiva que atua entre a Ideia e os fenômenos, a primeira é a apreensão adequada do sentido íntimo dos fenômenos. Além disso, o filósofo também solicita o apoio do idealismo kantiano ao assimilar a oposição entre fenômeno e coisa em si, ambas doutrinas negam aos fenômenos a realidade verdadeira.

Diante da dificuldade manifesta de conciliar o dogmatismo de Platão ao criticismo kantiano, Schopenhauer nota simplesmente que o primeiro não foi até o fim do caminho começado; partindo da recusa do real aparente ele teria que considerar abertamente as formas

\footnotetext{
6 * “Tempo e espaço são o principium individuationis” (...). O princípio de individuação compreende, portanto, dois terços do princípio de razão suficiente, amputado abstratamente da causalidade, já que ela resulta da reunião do espaço com o tempo. Ele "pertence ao terreno da simples aparência" (...). Logo, seja ele qual for, o indivíduo não passa de uma ilusão fenomênica. ** "Chamarei, portanto o espaço e o tempo, segundo uma velha expressão da escolástica, de principium individuationis, pois é por intermédio do espaço e do tempo que o que é um e semelhante em sua essência e em seu conceito aparece para nós como diferente, como vários, seja na ordem da coexistência seja na da sucessão" (...) Schopenhauer adota dois pontos de vista quando trata da representação fenomênica. Quando quer destacar a organização, ou seja, a ligação causal, invoca o princípio de razão suficiente. Se, ao contrário, pretende insistir em sua diversidade, recorre ao princípio de individuação, que depende dessas duas formas a priori da disseminação representativa que são o espaço e o tempo (...). *** A Vontade, una, indivisível e intemporal, enquanto coisa em si foge ao princípio de individuação, ainda que, por uma razão misteriosa, independente do princípio de razão, ela se pluralize em Ideias (...) que são objetidades imediatas [conforme mencionamos]. Dessa diversidade metafísica, e já não fenomênica, Schopenhauer não dá explicação (ROGER, 2013, pp. 6061). Seja observado que o próprio filósofo adjudica a Vontade como "sem-fundamento" [Grundlos].
} 
do mundo sensível como fenomenais, ao passo que as Ideias, consideradas sob o aporte da crítica transcendental não são intermediário entre a coisa em si e o fenômeno, mas representações reguladoras, conquanto, tem efeito postulado para a razão prática.

Somente o abandono da representação submetido ao princípio de razão ligado ao fenômeno, permite ao homem tornar-se sujeito puro do conhecimento. Essa condição aparentemente negativa se converte num estágio de transição positiva, na intelecção da Ideia. Lembremos que o alcance de tal inteligibilidade só é acessível a quem de deixou de conhecer enquanto indivíduo. Essa supressão [Aufhebung] é requerida na medida em que o corpo é objetivação da Vontade. A inteligência contemplativa se destaca do querer veemente, destarte as representações que chegam até ao sujeito não mais são motivos apreciados indispensáveis.

\begin{abstract}
Para conceber [Auffaßung] uma Ideia [Idee] e permitir a sua entrada em nossa consciência, precisamos de uma mudança em nós mesmos, a qual pode ser tomada também como uma ato de negação [Akt der Selbstverläugnung]. Desse modo, consiste em que o conhecimento se afaste totalmente de nossa vontade e, assim, deixando totalmente fora da vista a promessa preciosa que lhe foi confiada, considere as coisas como se elas nunca pudessem, de nenhum modo, dizer respeito à vontade. Pois, só assim é que o conhecimento se torna espelho puro [reinen Spiegel] do ser objetivo das coisas do ser objetivo das coisas. Um conhecimento assim tão condicionado deve ser o fundamento de toda genuína obra de arte, bem como a sua origem. A mudança no sujeito é necessária para isso, apenas porque consiste consiste na eliminação de todo querer, não pode prosseguir a partir da vontade ou, por outras palavras, não pode persistir em nós. Pelo contrário, da prevalência temporária da vontade sobre o intelecto, ou de um ponto de vista fisiológico, a partir de uma forte excitação [starken Erregung] da atividade intuitiva do cérebro [anschauenden Gehirnthätigkeit], sem qualquer excitação das inclinações ou afetos. Para explicar isto de modo um pouco mais preciso, lembro ao leitor que a nossa consciência tem dois lados. Parte dela é consciência de nós mesmos que é a vontade, e parte é a consciência de outras coisas. Assim, ela é principalmente conhecimento do mundo externo através da intuição, isto é do discernimento [Einsicht] dos objetos (SCHOPENHAUER, 2015, pp. 19-20).
\end{abstract}

Essa experiência vivida subjetivamente como liberação do desejo, deixa entrar na vacuidade a Ideia, como aquilo que preenche preenche o sujeito efetivamente, de maneira intensa, mais do que os outros objetos desejados largados à beira da insatisfação ainda em sua violenta avidez. É um olhar libertado das correntes do querer, essa libertação nos salva da dor.

III.

O "gosto" é, segundo Kant, a faculdade de julgar um objeto de uma maneira desinteressada [ohne Interesse]. "Chama-se de belo o objeto dessa satisfação". O mesmo vale para Schopenhauer: a contemplação estética e o prazer que ela proporciona são desinteressados. Mas ele abandona os outros três momentos da análise kantiana: a 
universalidade sem conceito [ohne Begriff], a finalidade sem fim [ohne Zweck] e a necessidade sem conceito. A experiência do belo é, pelo contrário, objetiva, já que o sujeito que o contempla, assim como o artista que o produz, alcança uma objetidade da Vontade. Com efeito, o que ele vê não é um fenômeno ilusório e transitório, é uma Ideia, o que exige uma dupla liberação: do lado do objeto, que se despoja de sua aparência fenomenal e do sujeito que se emancipa dos tormentos da vontade, ambas as operações indissolúveis.

Dizer que uma coisa é bela equivale exprimir que ela é objeto de nossa contemplação estética; implica, em primeiro lugar que, a visão dessa coisa, nos torna objetivos, ou seja, que ao contemplá-la temos pura consciência de nós mesmos. Assim, o homem que se limita a contemplar, entregue plenamente à imagem do objeto, de modo a isolar o aspecto de representação do mundo (e isso ocorre no mais alto grau quando ele está diante da obra de arte) esse homem perdeu sua determinação como indivíduo concreto e causal, apartando-se dos elementos do mundo que não mantém relação com essa intuição momentânea. Esse caráter momentâneo faz com que a essência da intuição estética seja atemporal.

Eis aí o núcleo da atividade estética. Concordando com Simmel (2010), ela se dissocia plenamente o mundo como representação e o mundo como Vontade. A existência das coisas separa-se da vontade em nosso intelecto, passando a ocupar uma esfera própria. Nem mesmo o Eu mantém uma existência independente; também se dissolve na imagem, na representação. A salvação pelo estado estético é uma inversão radical da condição humana: ela pode ocorrer diante de qualquer objeto, sempre que o conteúdo deste (fixado em uma representação e sem servir a nenhum interesse da vontade) nos preencha. Consideramos belos os objetos que facilitam contemplar uma imagem separada de toda vontade, e o artista genial é o homem que consegue isso de modo mais pleno e mais perfeito que os demais. De certo modo, a obra de arte nos força a contemplá-la: com ela, o conteúdo das coisas e dos destinos se eleva a uma existência própria, afastado de toda complicação com o desejo ou com o meramente prático, como Schopenhaeur diz maravilhosamente em uma passagem: “A arte sempre chegou ao fim". Situada entre o gênio criador e o indivíduo receptivo, a arte é ao mesmo tempo efeito e causa da emancipação do puro intelecto a em relação à vontade. Nasce daí toda a significação que ela tem na metafísica schopenhaueriana ${ }^{7}$.

\footnotetext{
7 Como vontade, fora da representação e de todas as suas formas, ela é uma e a mesma, no objeto contemplado, e no indivíduo que, elevando-se por esta contemplação, se torna consciente de si como puro sujeito; estes dois por isto não são em si diferenciáveis, pois em si são a vontade que se conhece a si mesma, e é somente do modo pelo qual este conhecimento se lhe constitui, i. e., somente no fenômeno, graças à sua forma, o princípio de razão, multiplicidade e diversidade. Tampouco eu, sem o objeto, sem a representação, sou sujeito que conhece, mas tão-somente simples vontade cega; tampouco sem mim, como sujeito do conhecimento, a coisa conhecida é objeto, mas tão-somente simples vontade, ímpeto cego. Esta vontade é em si, i. e., fora da representação, idêntica a minha própria; somente no mundo como representação, cuja forma é sempre pelo menos sujeito e objeto, nos separamos como indivíduo conhecido e conhecedor. Suprimido o conhecedor, o mundo
} 


\title{
É digna de passagem,por mais ligeiramente extensa que seja, para recapitular
}

\author{
sinteticamente o compreendido até agora, o parágrafo de abertura da seção que trata duma
} contribuição para a „Metafísica do belo e a Estéticae [Zur Metaphysik des Schönen und Aesthetik] no segundo tomo dos Parerga e Paralipomena, seja-nos permitido vislumbrar o "resumo da ópera" nas palavras do próprio Schopenhauer:

(...) $\mathrm{O}$ verdadeiro problema da metafísica do belo se pode formular de maneira muito simples: como é possível a complacência e a alegria em um objeto sem referência nenhuma deste a nosso querer?

Com efeito, cada qual sente que a alegria e a complacência em uma coisa não podem nascer na realidade mais do que sua relação com nossa vontade ou, como gostamos de expressá-lo, com nossos fins; de modo que uma alegria sem excitação da vontade parece ser uma contradição. Não obstante, está totalmente claro que o belo suscita enquanto tal nossa complacência, nossa alegria, sem ter relação alguma com nossos fins pessoais, isto é, com nossa vontade.

Minha solução foi que no belo captamos sempre as formas essenciais e originais da natureza viva e inerte, vale dizer, suas ideias platônicas, e que essa captação tem como condição seu correlato essencial, o sujeito involuntário do conhecimento, isto é, uma inteligência pura sem propósitos nem fins. Deste modo, ao aparecer a captação estética, a vontade desaparece totalmente da consciência. Mas ela é a única fonte de todas nossas aflições e sofrimentos. Essa é a origem daquela complacência e aquela alegria que acompanham a captação do belo. Se baseia, pois, na supressão de toda possibilidade de sofrimento. - Se se quiser por acaso objetar que então se suprimiria a possibilidade da alegria, haveria de recordar que, como demonstrei amiúde, a felicidade, a satisfação, é de natureza negativa, em concreto não é mais que o fim de um sofrimento, enquanto que a dor é o positivo. Daqui que ao desaparecer todo querer da consciência se mantenha o estado de alegria, vale dizer, da ausência de qualquer dor, e inclusive da ausência de sua possibilidade; porque o indivíduo, transformado em um sujeito puro do conhecimento que já não quer, segue sendo consciente de si mesmo e de sua atividade justamente enquanto tal. Como sabemos, o mundo como vontade é o primeiro mundo (ordine prior); e o mundo como representação, o segundo (ordine posterior). Aquele é o mundo do desejo e, portanto, da dor e das mil desgraças. O segundo é em si mesmo essencialmente indolor: ademais, contém um espetáculo digno de ver-se, plenamente significativo e quando menos divertido. Em seu desfrute consiste a alegria estética. Converter-se em puro sujeito do conhecimento significa liberar-se a si mesmo: mas, posto que a maioria dos homens não pode fazê-lo, são ordinariamente incapazes de captar as coisas de forma puramente objetiva, que é o que constitui o dom do artista (SCHOPENHAUER, 2005, pp. 429-430 (trad. do autor $)^{8}$.

como representação, nada resta além de simples vontade, ímpeto cego. Que ele adquira objetividade, se torne em representação, instaura de um golpe tanto no sujeito como no objeto: porém que esta objetividade seja objetividade pura, perfeita, adequada da vontade, instaura o objeto como idéia, livre das formas do princípio de razão, e o sujeito como puro sujeito do conhecimento, livre de individualidade e servidão para a vontade (Id., ibid., p.32).

8 (...) Das eigentliche Problem der Metaphysik des Schönen läßt sich sehr einfach ausdrücken: wie ist Wohlgefallen und Freude an einem Gegenstand möglich, ohne irgend eine Beziehung desselben auf unser Wollen?

Jeder nämlich fühlt, daß Freude und Wohlgefallen an einer Sache eigentlich nur aus ihrem Verhältniß zu unserm Willen, oder, wie man es gern ausdrückt, zu unsern Zwecken, entspringen kann; so daß eine Freude ohne Anregung des Willens ein Widerspruch zu seyn scheint. Dennoch erregt, ganz offenbar, das Schöne als solches unser Wohlgefallen, unsre Freude, ohne daß es irgend eine Beziehung auf unsre persönlich Zwecke, also unsern Willen, hätte.

Meine Lösung ist gewesen, daß wir im Schönen allemal die wesentlich und ursprünglichen Gestalten der belebten und unbelebten Natur, also Plato "s Ideen derselben, auffassen, und daß diese Auffassung su ihrer Bedingung ihr wesentliches Korrelat, das willensreine Subjekt des Erkennens, d. h. eine reine Intelligenz ohne Absichten und Zwecke, habe. Dadurch verschwindet, beim Eintritt einer ästhetischen Auffassung, der Wille ganz aus dem Bewußtseyn. Er allein ist die quelle aller unserer Betrübnisse und Leiden. Dies ist der Ursprung jenes Wohlgefallens und jener Freude, welche die Auffassung des Schönen begleitet. Sie beruht also auf der Wegnahme der ganzen Möglichkeit des Leidens. - Wollte man etwan einwenden, daß dann auch die Möglichkeit der Freude aufgehoben wäre; so ist man zu erinnern, daß, wie ich öfter dargethan habe, das 
"As coisas são mais ou menos belas conforme facilitem e provoquem em maior ou menor medida a contemplação puramente objetiva". Mas a "beleza superior de um objeto provém do fato de que a Ideia que nos fala por meio dele correspondendo a um alto grau de objetivação da vontade" segundo uma hierarquia que vai da força ao caráter inteligível, passando pela espécie. "Eis por que a beleza humana supera toda outra beleza, eis também porque a representação da essência do homem é o objetivo mais elevado da arte". A Beleza é potencialmente universal: "Porque, por um lado, toda coisa dada pode ser considerada de maneira puramente objetiva, fora de qualquer relação; porque por outro lado, a Vontade se manifesta em cada coisa num grau qualquer de sua objetidade"; portanto, cada coisa "é a expressão de uma Ideia, segue-se que toda coisa é bela". Logo o sistema de Schopenhauer não é apenas um "pantelismo" (Tudo é Vontade), mas também um "pancalismo" (Tudo é belo). A sabedoria vedanta nos diz: "Hae omnes creaturae in totum ego sum, et praeter me aliud ens non est" (Sou todas essas criaturas em conjunto, e fora de mim não há nenhum outro ser). Tat twan asi, do sânscrito: isto és tu, se expressa igualmente magnífica.

\section{Considerações finais}

Segundo a interpretação evocada, a concepção de Ideia (ou mesmo species) suscita o tipo originário [Urtype], ou seja, a forma eterna, incondicionada por tempo, espaço e causalidade, vale dizer, fora do alcance das figuras do princípio de razão [Satz vom Grunde]: figuras do intelecto, assim sendo fiel ao sentido dado por Platão. Deste modo, volvendo a Kant, o conhecimento puro da Ideia, está intimamente ligado ao da coisa-em-si, entretanto, difere toto genere dela mesma, na medida em que, reconhecida metafisicamente como Vontade, entra em cena, na enorme escala dos seres existentes, objetivando gradativamente o querer-viver [Wille zum Leben] infrene, propagado na multiplicidade, hierarquicamente, do reino mineral ao vegetal até chegar ao ápice de sua autoconsciência [Selbstbewußtsein]: o homem; esta série acabada, se chama objetidade-da-Vontade, graus ideais, espécies, que por

\footnotetext{
Glück, die Befriedigung, negativer Natur, nämlich bloß das Ende eines Leidens, der Schmerz hingegen das Positive ist. Daher bleibt, beim Verschwinden alles Wollens aus dem Bewußtseyn, doch der Zustand der Freude, d. h. der Abwesenheit alles Schmerzes, und hier sogar der Abwesenheit ser Möglichkeit desselben, bestehen, indem das Individuum, in ein rein erkennendes und nicht mehr wollendes Subjekt verwandelt, sich seiner und seiner Thätigkeit, eben als eines solchen, doch bewußt bleibt. Wie wir wissen, ist die Welt als wille die erste (ordine prior) und die als Vorstellung die zweite Welt (ordine posterior). Jene ist die Welt des Verlangens und daher des Schmerzes und tausendfältigen Wehes. Die zweite aber ist an sich selbst wesentlich schmerzlos: dazu enthält sie ein sehenswerthes Schauspiel, durchweg bedeutsam, aufs Wenigste belustigend. Im Genuß desselben besteht die ästhetische Freude.- Reines Subjekt des Erkennens werden, heißt, sich selbst loswerden. Das reine subjekt des Erkennens tritt ein, indem man sich vergißt, um ganz in den angeschauten Gegenständen aufzugehen; so daß nur sie im Bewußtseyn übrig bleiben. Weil aber Dies die Menschen meistens nicht können, sind sie zur rein objektiven Auffassung der Dinge, welche die Begabung des Künstlers ausmacht, in der Regel, unfähig (PP II, §209, pp. 447-448).
} 
sua vez, podem ser adequadamente contempladas por uma vitória do intelecto sobre ela, abandonando-se o sujeito ao objeto como um espelho, essa é a atividade do sujeito puro do conhecimento que pretendemos esmiuçar. Agora bem, a arte reproduz as Ideias eternas que ela concebeu por meio da contemplação pura, sua única origem é o conhecimento delas, sua exclusiva finalidade é a comunicação desse conhecimento. Ela é própria do gênio [Genie] que possui, portanto, a dupla capacidade de contemplar as Ideias, ou objetidades imediatas da Vontade [unmittelbare Objektität des Willens], e de transmiti-las pela produção das obras que são a "cópia" [Abbild] dessas Ideias. A estética e a metafísica do belo schopenhaueriana, destarte, coloca a ênfase na contemplação das Ideias como condição fundamental da atividade artística; sobrepondo-o ao conhecimento racional, submetido ao princípio de razão suficiente, que "só tem valor na vida prática e na ciência". Essa fruição platônica cuja reprodução constitui a obra de arte, em última instância, é somente o meio destinado a facilitar o conhecimento da Ideia, conhecimento que resulta no prazer estético. Na filosofia de Schopenhauer, à inteligibilidade da Ideia, é concedida, assim, uma eminente "dignidade metafísica", já que sua reprodução e contemplação, tão essenciais, são muito superiores em relação aos outros objetos do mundo fenomênico das representações.

\section{Referências:}

DOS SANTOS DURANTE, Felipe. A Escola de Schopenhauer em seus sentidos lato e estrito: entre Apóstolos, Evangelistas, Metafísicos, Heréticos, os Pais da Igreja e as Mulheres. Sofia, v.6, n. 1, p. 136-148, 2017.

PERNIN, Marie-José. Schopenhauer: decifrando o enigma do mundo. Rio de Janeiro: Jorge Zahar Ed., 1995

ROGER, Alain. Vocabulário de Schopenhauer. Trad. Claudia Berliner. São Paulo: WMF Martins Fontes, 2013.

SHOPENHAUER, Arthur; BECKER, Johann August. Briefwechsel zwischen Arthur Shopenhauer und Johann August Becker. Erst. Aufl. Leipzig, Brockhaus, 1883.

. Metafísica do belo. Trad. Jair Barboza. São Paulo: Ed. Unesp, 2003.

O mundo como vontade e representação, Tomo II, vol. 1 e 2. - Complementos. Trad. Eduardo Ribeiro da Fonseca. Curitiba: Ed. UFPR, 2015

O Mundo como Vontade e Representação (parte III) Coleção Os Pensadores. Trad.

Wolfgang Leo Maar. Editora Nova Cultural Ltda. São Paulo (SP), 1997. 
Parerga und paralipomena. Dritte. Aufl. Leipzig. JG Cotta ${ }^{a e}$ sche buchhandlung nachfolger, 1874.

Parerga y Paralipomena II. Tradução de Pilar López de Santa María. Madrid: Editorial Trotta, 2007.

SIMMEL, Georg. Schopenhauer e Nietzsche. Trad. Cesar benjamim. - Rio de Janeiro: Ed. Contraponto, 2010.

Data de registro: $27 / 11 / 2018$

Data de aceite: 27/03/2019 